in our knowledge of the Coleoptera over the whole range of their biology, making one of the most valuable features of the book.

Taken together with its encyclopaedic coverage, these indications of our ignorance will enable The Biology of the Coleoptera to provide many potential researchers with a starting point, a basic literature survey and a summary of current knowledge. This is one of the most important books on beetles to be published this century, and it is the first modern text on their biology. I hope it will be bought by many entomologists, evolutionary biologists and science libraries.

M.E.G. Evans is Senior Lecturer in Zoology at the University of Manchester.

\section{Puzzles of perception}

\section{Oliver Braddick}

Direct Perception. By Claire F. Michaels and Claudia Carello. Pp.200. ISBN 0-13-214791-2. (Prentice-Hall: 1981.) £13.50, \$24.30.

THE perceptual psychologist J.J. Gibson (1904-1979) wrote a series of books which crystallized a theoretical stance he called "ecological optics" and "direct perception". The books were widely read and many details from them became absorbed as standard textbook material, but it seemed for many years that Gibson's basic position was a lonely, almost ignored one, outside the mainstream of thinking on perception. It is still outside the mainstream, but in the years just before and since Gibson's death it has gathered such a vigorous, even strident, group of younger advocates that no one in the field has an excuse for being unaware of it. There has been a particularly zealous Gibsonian cell in and around the University of Connecticut, two of whose members have produced this short, clear, didactic book.

The view against which the authors argue is that the perceiving organism takes in at the sense organs a collection of "raw data" whose relation to objects in the external world is distant and often incomplete, and that the task of perceptual psychology is to discover the computations by which information about the external world is obtained or inferred from these data. The alternative they propose is that perception has to be considered as a function of a system consisting of organism and environment, that the ecologically relevant properties of the environment are present as higher-order invariants in the pattern of energy reaching the senses, and may be detected because the perceptual system "resonates" directly to these higher-order invariants, rather than computing or inferring anything. Some other advocates of this position have presented it in a manner that appeared to relish shocking, mystifying or finessing more conventional views; here the argument is more orderly and well paced, with its progress charted in summaries of each chapter and at the end of the book. An appendix, "Discussion and Debate", which deals with some queries and criticisms of the argument in question-andanswer form, is very helpful in clarifying just what the authors' position is, although as a debate it is distinctly stage-managed.

It is a valid criticism of much work in sensory and perceptual psychology that it does not give enough thought to what perception is for, or to whether the stimulus variables that are manipulated in perceptual experiments bear any relation to the variables the perceiver needs to use. The opponent that the book sets up is therefore not a straw man, but he lacks flesh in a way that the Gibsonians blithely ignore. The information-processing tradition is centrally interested in problems of mechanism; not only (indeed, not enough) in what job perceptual systems do, but also in how they work. For instance, Michaels and Carello argue that the direct perception approach undercuts the two "puzzles in binocular vision" which have been "an object of discussion for three millenia" - how can a pair of twodimensional retinal images yield a 3-D percept, and how can it be single? No awareness is indicated that the major binocular puzzle that has interested scientists in the last two decades is not of this kind but is "What kind of mechanism finds pairs of corresponding elements in the two eyes' images?"'. Now analysis of ecological optics might suggest that this question should be posed in a somewhat different form, but identification of the relevant invariants in the optic array does not abolish the question, how does the system work which "resonates" to them? It is difficult to see how such an answer can be cast except in terms of signals relayed by the sense organs and operations performed upon these signals.

For this reason, scientists working in the information-processing and psychophysical traditions are likely to be impatient with much of Direct Perception. What they would find it hard to deny is that most of the experimental work generated by the direct perception school has been interesting - something they would have to be very partisan to assert of their own tradition. It is perhaps a pity that Michaels and Carello did not make their book 50 pages longer and give us a more detailed awareness of how their approach bears scientific fruit - in the experimental and analytical work of Lee, Shaw and Turvey, among others.

Oliver Braddick is a Lecturer in Experimental. Psychology at the University of Cambridge.

\section{Bones into stones}

\section{Mark Newcomer}

Life History of a Fossil: An Introduction to Taphonomy and Paleoecology. By Pat Shipman. Pp.222. ISBN 0-674-53085-3. (Harvard University Press: 1981.) \$25, $£ 14$.

PAlaeontologists are no longer content to classify, weigh, measure and tabulate fossil bones, and are bringing their subject out of the museum through studies of the processes by which the fossil record forms (taphonomy) and through reconstructions of extinct animal communities in their environmental setting (palaeoecology). Recent work in these fields, which to some degree parallels that of archaeologists who attempt to see their sites and artifacts in their geographical context, is the subject of Pat Shipman's lively text.

Much of the book concentrates on the principles, methods of study and results of taphonomic studies of (mainly) African vertebrates, reflecting the author's research interests and competence. She treats her material critically, steering a cautious course through such murky waters as the spiral fracture debates, and stresses the value of suitable quantitative methods for many taphonomic and palaeoecological problems; her comments on excavation procedures and "living floors", however, seem a little naive, especially in light of all the recent publications on these matters. (Why does the long reference list contain only Englishlanguage publications? Curious in a book intended as a text.) Without sounding arrogant, I think it is fair to say that standards of excavation have generally been higher in archaeology than in palaeontology, with the fossil hominid hunters perhaps the most culpable, relying on the spectacular nature of their finds to obscure excavation methods which are often mediocre or worse. Similarly, the author could have gone more deeply into the role of hominids in creating both the types and spatial patterns of refuse on sites, given recent experimental work and ethnographic studies by Binford and Yellen, among others.

Intended for "advanced undergraduate courses in anthropology, palaeontology, and evolutionary biology", as well as professionals in these fields, Life History of a Fossil will serve as an excellent introduction to taphonomy and palaeoecology. It should also reach a much wider audience with less specialized interests in vertebrate evolution, to whom the lessons to be learned from humble, often broken, bones will come as a pleasant surprise.

Mark Newcomer is a Lecturer in Palaeolithic Archaeology at the Institute of Archaeology, London. 